\title{
The Voice Test for Newborn Hearing Screening
}

\author{
Teresa Luisa I. Gloria-Cruz, ${ }^{1,2}$ Genereso T. Abes ${ }^{1,2}$ and Franco Louie LB. Abes ${ }^{1,2}$ \\ 1Philippine National Ear Institute, National Institutes of Health, University of the Philippines Manila \\ ${ }^{2}$ Department of Otorhinolaryngology, College of Medicine and Philippine General Hospital, University of the Philippines Manila
}

\begin{abstract}
Objectives. The goal of the study is to find a reasonable alternative test that can be utilized in the Philippine setting to operationalize the Universal Newborn Hearing Screening Act. Thus the components of the Voice Test were studied. The objectives of the study are to determine: (1) which of the two words "Baah" and "Psst" is better for newborn hearing screening procedure as far as their physical characteristics are concerned, (2) how do the two words "Baah" and Psst" differ between genders and distance from sound source, (3) to determine the proportion of the participants who could recite the words at intensity of $80 \mathrm{db}$ or louder.
\end{abstract}

Methods. Frequency characteristics and sound intensity differences of two words "Baah" and "Psst" were determined and compared.

Results. The word "Baah" exhibited more favorable physical attributes over the word 'Psst" for purposes of being a screening tool for newborn hearing assessment.

Conclusion. This study reports the results of an initial step in the search for an inexpensive, feasible, and valid tool for neonatal hearing screening. Correlation studies with speech developmental milestones may eventually enhance the usefulness of the voice test.

Key Words: voice test, alternative hearing test, newborn hearing screening

\section{Introduction}

Objective physiologic examinations such as the Otoacoustic Emissions (OAE) test and the Acoustic Brainstem Response (ABR) test are globally recommended for use in universal hearing screening programs. ${ }^{1}$

According to the 2006 Family Planning Survey done by the National Statistics Office - Philippines, 6 out of 10 birth deliveries or 56.5 percent of babies are born at home. ${ }^{2}$ Among these newborns, majority have no access to objective

Corresponding author: Teresa Luisa I. Gloria-Cruz, MD

Department of Otorhinolaryngology

Philippine General Hospital

University of the Philippines Manila

Taft Avenue, Ermita, Manila 1000 Philippines

Telephone: +6325264360

Email: techgloriacruz@yahoo.com physiologic tests because of financial constraints, geographic challenges and inaccessibility to adequate healthcare facilities. There is now a need for a family-centered alternative test in order to heighten awareness among Filipinos regarding bilateral profound hearing loss among newborns, since immediate intervention is needed in children identified with deafness. Early intervention measures to improve hearing, such as hearing aid use and cochlear implantations, have shown improvements in the development of the central auditory pathways as well as improvements in the chance for speech and cognitive development. ${ }^{3}$

The whispered voice test has gained popularity in screening of both children and adults, especially among physicians in general practice. ${ }^{4}$ The procedure can easily be done by medical practitioners and trained paramedical personnel. The weakness of this test is that it cannot be performed on newborn infants because of the nature of the procedure, in which it requires the patient being tested to repeat the whispered words.

Although plagued by a high number of false-positive and false-negative responses, behavioral observation audiometry has been demonstrated to be useful in term gestation babies. In this test, a sound is presented that is loud enough in order to stimulate the baby. A positive response to the stimulus may be in the form of a provoked arousal (generalized body movement), a startle reflex (a jump), or an auropalpebral reflex (i.e. eye blinking by the awake baby, or eyelid tightening by the asleep baby). The stimulus must be purely auditory without any visual cues in this form of test. ${ }^{5}$

In the Philippines, two "generic" words are usually employed to call or get the attention of a person, these words are "Psst" and "Baah".

A free field voice test using the words "Baah" and "Psst" would potentially test for both high frequency and low frequency sound perception. Hypothetically, by saying the word "baah" a low frequency sound would be produced since the word consists mostly of vowels; on the other hand the sound "psst" would stimulate the high frequency end of the sound spectrum since it consists of consonants. These words can potentially be used if an appropriate method for testing can be done and if an acceptable response from the newborn may be observed upon doing the test. By introducing the two words, high frequency to low frequency 
cochlear hair cells would theoretically be stimulated. Once proven appropriate for newborn hearing screening, this simple test may be used in the future by parents, midwives and barangay health workers involved in the newborn hearing screening program.

This study aims to measure the range of frequencies stimulated, the sound intensity delivered, and the variability between the sounds "baah and "psst" when uttered by individuals 16-75 years old. This will show which among the two words is better with regard to the range of frequencies stimulated within the sound frequency spectrum. The method on how the tests should be carried out shall be known. It shall be resolved which test has less variability in terms of intensity in $\mathrm{db}$ SPL amongst males and females. At the end of the study, it will be sought out if the subjects can vocalize the words louder than $90 \mathrm{db}$ SPL, since newborns who cannot perceive sound at this sound intensity may be classified as profoundly deaf. The number of subjects who can and who cannot say the words at certain intensities will be determined as well.

\section{Methods}

The sounds "bah" and "psst" were recorded from 8 males and 8 females with ages ranging from 20 to 30 years old, using a Shure SM58 dynamic unidirectional microphone hooked to a Native Instruments Audio 8 DJ sound card. The sound card was connected to an Apple MacbookPro $2.53 \mathrm{GHz} 13$ inch laptop computer. Each individual was asked to take two deep breaths and relay the sound "bah" and "psst" with maximal exertion 6 inches away from the microphone. Every individual repeated the sequence of taking two deep breaths and producing the sound "bah" with maximal exertion for three consecutive times. The sound "psst" was likewise repeated for three times in the same way. Using the Adobe Soundbooth CS4 version 2.0 software, the range of frequencies occupied by the sounds "bah" and "pssst' were visualized and analyzed with respect to the range of frequencies emitted by each sound. The range of frequencies from each sound was determined and then tabulated.

Another group of randomly selected individuals, 50 males and 43 females ages 16 to 75 years, were asked to stay in a quiet room (ambient noise average $=55 \mathrm{db}$ SPL) in which each individual was asked to say the sound "baah" with maximum exertion after two deep breaths from a one meter distance into a calibrated sound level meter pointing towards the subject 3 feet from the ground. The "baah" test was done three times for each individual at which the SPL $\mathrm{dB}$ level was recorded for each trial. Each time that the volunteer would say the word "baah", he or she was asked to take two deep breaths first before he would say the word with maximal exertion. The test was again repeated from a two meter distance using the same procedure by the same individual and was also done three times with decibel levels determined for each trial. The sound "psst" was also tested from a one meter and from a two meter distance using the same procedure for the "baah" test. A Tecpel Model 332 Sound level Meter was used to record the SPL decibel level for each trial.

The mean of the three trials done from both a distance of one meter and a distance of two meters were computed for both the "baah" and the "psst" test. The results of these averages were then tabulated and subsequently analyzed using the student's unpaired t-test. T-test results were derived and computed via an online calculator. (http:// www.graphpad.com/quickcalcs/ttest2.cfm)

The mean for the "baah" test and the "psst" test were also stratified into sounds equal to or greater than $90 \mathrm{db}$, sounds equal to or greater than $80 \mathrm{db}$, and sounds equal to or greater than $70 \mathrm{db}$. A z-test for two proportions was done in order to analyze the results between the male and female populations via an online calculator as well. (http://www.dimensionresearch.com/resources/calculators/z test.html)

\section{Results and Discussion}

Upon frequency analysis, the male "baah" sound was noted to stimulate sound frequency ranges starting from $100 \mathrm{hz}$ up to 5000hz. The female "baah" sound occupied sound frequencies ranging from $150 \mathrm{hz}$ up to $5000 \mathrm{hz}$. The male "psst" sounds stimulated sound frequencies starting from $2000 \mathrm{hz}$ up to $15000 \mathrm{hz}$. The female "psst" sounds stimulated sound frequencies ranging from $2000 \mathrm{hz}$ up to 15000hz.

The values in Table 1 show that the frequency range stimulated by the "Baah" sound was from $150 \mathrm{hz}$ up to $5000 \mathrm{hz}$, thus indicating sound stimulation from low to high frequencies with the use of this sound. With this in mind, it must be noted that it is possible for a newborn not have high frequency sound perception yet may still retain residual low frequency sound perception.

It is shown in Table 2 that the frequency range stimulated was from $2000 \mathrm{hz}$ up to $15000 \mathrm{hz}$ indicating high frequency stimulation with the "psst sound". Thus, if this sound is to be used as a voice test, newborns with residual low frequency hearing perception may show an abnormally absent response.

Table 3 shows that the "Baah" sound had no significant difference whether it was done from a 1 meter or from a 2 meter distance. On the other hand, the "Psst" sound had mean intensity values (dbSPL) that were significantly different when measured from a 1 meter and from a 2 meter distance. The mean intensity values of "baah" were significantly louder than "psst" when it was done from a distance of both 1 meter and 2 meters. 
Table 1. Sound Wave Comparison for Baah (frequency range in $\mathrm{Hz}$ )

\begin{tabular}{lcccc}
\hline BAAH & $\begin{array}{c}\text { Lowest } \\
\text { freq(Hz) }\end{array}$ & $\begin{array}{c}\text { Highest } \\
\text { freq } \mathbf{( H z )}\end{array}$ & $\begin{array}{c}\text { Frequency } \\
\text { Range } \mathbf{( H z )}\end{array}$ & $\begin{array}{c}\text { Mean frequency in } \\
\text { Hz (from 3 trials) }\end{array}$ \\
\hline Male 1 & 100 & 4000 & $100-4000$ & 1966.67 \\
Male 2 & 100 & 4000 & $100-4000$ & 2466.67 \\
Male 3 & 100 & 4000 & $100-4000$ & 2050 \\
Male 4 & 100 & 4500 & $100-4500$ & 2300 \\
Male 5 & 100 & 4000 & $100-4000$ & 2050 \\
Male 6 & 100 & 5000 & $100-5000$ & 2550 \\
Male 7 & 100 & 4000 & $100-4000$ & 2050 \\
Male 8 & 100 & 3500 & $100-3500$ & 1800 \\
Overall & $\mathbf{1 0 0}$ & 5000 & $\mathbf{1 0 0 - 5 0 0 0}$ & $\mathbf{2 1 5 4 . 1 7}$ \\
Female 1 & 150 & 5000 & $150-5000$ & 2408.33 \\
Female 2 & 150 & 4500 & $150-4500$ & 2325 \\
Female 3 & 200 & 5000 & $200-5000$ & 2475 \\
Female 4 & 200 & 4000 & $200-4000$ & 2100 \\
Female 5 & 150 & 5000 & $150-5000$ & 2450 \\
Female 6 & 150 & 5000 & $150-5000$ & 2575 \\
Female 7 & 150 & 4000 & $150-4000$ & 2075 \\
Female 8 & 150 & 4000 & $150-4000$ & 2075 \\
Overall & $\mathbf{1 5 0}$ & $\mathbf{5 0 0 0}$ & $\mathbf{1 5 0 - 5 0 0 0}$ & $\mathbf{2 3 1 0 . 4 2}$ \\
\hline
\end{tabular}

Table 2. Sound Wave Comparison for Psst (frequency range in $\mathrm{Hz}$ )

\begin{tabular}{lcccl}
\hline Psst & Low(Hz) & High(Hz) & Range & $\begin{array}{c}\text { Mean } \\
\text { (from 3 trials) }\end{array}$ \\
\hline Male 1 & 2500 & 15000 & $2500-15000$ & 8750 \\
Male 2 & 3000 & 14000 & $3000-14000$ & 8166.67 \\
Male 3 & 3000 & 14000 & $3000-14000$ & 8000 \\
Male 4 & 6000 & 14000 & $6000-14000$ & 10000 \\
Male 5 & 3000 & 15000 & $3000-15000$ & 9000 \\
Male 6 & 2000 & 15000 & $2000-15000$ & 8500 \\
Male 7 & 2500 & 15000 & $2500-15000$ & 8750 \\
Male 8 & 2000 & 14000 & $2000-14000$ & 8000 \\
Overall & $\mathbf{2 0 0 0}$ & $\mathbf{1 5 0 0 0}$ & $\mathbf{2 0 0 0 - 1 5 0 0 0}$ & $\mathbf{8 6 4 5 . 8 3}$ \\
Female 1 & 6000 & 15000 & $6000-15000$ & 10500 \\
Female 2 & 5000 & 15000 & $5000-15000$ & 10000 \\
Female 3 & 6000 & 15000 & $6000-15000$ & 10500 \\
Female 4 & 4500 & 15000 & $4500-15000$ & 9916.67 \\
Female 5 & 2000 & 15000 & $2000-15000$ & 8500 \\
Female 6 & 4000 & 15000 & $4000-15000$ & 9500 \\
Female 7 & 3000 & 15000 & $3000-15000$ & 9000 \\
Female 8 & 6000 & 15000 & $6000-15000$ & 10500 \\
Overall & $\mathbf{2 0 0 0}$ & $\mathbf{1 5 0 0 0}$ & $\mathbf{2 0 0 0 - 1 5 0 0 0}$ & $\mathbf{9 8 0 2 . 0 8}$ \\
\hline
\end{tabular}

Table 3. Comparison of Mean Intensity Values between Baah and Psst at 1 meter and 2 meters

\begin{tabular}{lllc}
\hline & 1 meter & 2 meters & P-value \\
\hline Bah & 92.94 & 91.13 & 0.2035 \\
Psst & 76.04 & 71.69 & 0.0098 \\
P-value & 0.0001 & 0.0001 & \\
\hline
\end{tabular}

Table 4. "Baah" Averages between males and females

\begin{tabular}{llll}
\hline & 1 meter & 2 meters & P-value \\
\hline Male & 92.93 & 92.02 & 0.9966 \\
Female & 92.96 & 90.09 & 0.1733 \\
P-value & 0.9966 & 0.9876 & \\
\hline
\end{tabular}

The averages seen in Table 4 show that there was no significant difference in mean intensity values (db SPL) for the "Baah" sound between males and females, whether it was tested from a distance of 1 meter or 2 meters. Hence, mean intensity was not different between sexes nor was it different between the distances of 1 meter and 2 meters.

Table 5. "Psst" averages between males and females

\begin{tabular}{llll}
\hline & 1 meter & 2 meters & P-value \\
\hline Male & 78.38 & 73.07 & 0.0305 \\
Female & 73.31 & 70.09 & 0.1427 \\
P-value & 0.0408 & 0.1427 & \\
\hline
\end{tabular}

Upon analysis of the "psst" sound, as seen in Table 5, there was a significant difference in sound intensity amongst males when measured from the 1 meter and from the 2 meter mark. A significant difference was also seen between males and females when the test was done at the 1 meter mark. Hence when doing the test, consistency in intensity values may be questionable.

The number of subjects who could produce the "baah" and "psst" sounds at 1 meter and 2 meters at an intensity of at least $90 \mathrm{db}, 80 \mathrm{db}$ and $70 \mathrm{db}$ were quantified, stratified and tabulated which then showed the following results:

Table 6-A. BAH test at 1 meter with intensity of $90 \mathrm{db}$ and above

\begin{tabular}{llll}
\hline & \multicolumn{2}{c}{$\mathbf{9 0} \mathrm{db}$} & $<\mathbf{9 0} \mathrm{db}$ \\
\hline Total & 56 & $(\mathrm{n}=93)$ & 37 \\
Males & 29 & $(\mathrm{n}=50)$ & 21 \\
Females & 27 & $(\mathrm{n}=43)$ & 16 \\
\hline
\end{tabular}

Table 6-A shows that 56 out of the 93 subjects or $60.22 \%$ could say the sound "baah" at $90 \mathrm{db}$ SPL or more from a 1 meter distance. $58 \%$ of males and $63 \%$ of females could utter the sound "baah" at that intensity from a 1 meter distance. When the Z- test was performed for the two proportions, a zvalue of 0.258 was derived which indicated no significant difference at a $95 \%$ confidence interval. Thus, it can be stated that the majority of the subjects could perform the bah test at an intensity of $90 \mathrm{db}$ SPL or more.

Table 6-B. BAH test at 1 meter with intensity of $80 \mathrm{db}$ and above

\begin{tabular}{llcll}
\hline & \multicolumn{2}{c}{$\mathbf{8 0} \mathbf{d b}$} & \multicolumn{3}{c}{$<\mathbf{8 0} \mathbf{d b}$} \\
\hline Total & 79 & $(\mathrm{n}=93)$ & 14 & $(\mathrm{n}=93)$ \\
Males & 43 & $(\mathrm{n}=50)$ & 7 & $(\mathrm{n}=50)$ \\
Females & 36 & $(\mathrm{n}=43)$ & 7 & $(\mathrm{n}=43)$ \\
\hline
\end{tabular}

Table 6-B shows that $84.95 \%$ could say the word bah at $80 \mathrm{db}$ SPL or more from a 1 meter distance. $86 \%$ of males and $84 \%$ of females could say the word from a one meter 
distance. A z-value of 0.016 was derived which showed no significant difference at a $95 \%$ confidence interval.

Table 6-C. BAH test at 1 meter with intensity of $70 \mathrm{db}$ and above

\begin{tabular}{lll}
\hline & $70 \mathrm{db}$ & $<70 \mathrm{db}$ \\
\hline Total & $90 \quad(\mathrm{n}=93)$ & $3(\mathrm{n}=93)$ \\
Males & $48 \quad(\mathrm{n}=50)$ & $2(\mathrm{n}=50)$ \\
Females & $42 \quad(\mathrm{n}=43)$ & $1(\mathrm{n}=43)$ \\
\hline
\end{tabular}

In Table 6-C, it is shown that $97 \%$ of the subjects could perform the "bah" test at $70 \mathrm{db}$ SPL or more from a one meter distance. $96 \%$ of males and $98 \%$ of females could perform the test at this threshold level. The $Z$ value $=-0.134$ and entailed no significant difference between the males and females who could perform the bah test at $70 \mathrm{~dB}$.

Table 7-A. BAH test at 2 meters with intensity of $90 \mathrm{db}$ and above

\begin{tabular}{lccc}
\hline BAH 2 meters & \multicolumn{9}{c}{$\mathbf{~ d b}$} & $<\mathbf{9 0} \mathbf{d b}$ \\
\hline Total & 53 & $(\mathrm{n}=93)$ & 40 \\
Males & 30 & $(\mathrm{n}=50)$ & 20 \\
Females & 23 & $(\mathrm{n}=43)$ & 20 \\
\hline
\end{tabular}

The values on Table 7-A show that from a 2 meter distance, 53 out of 93 (57\%) subjects could achieve an intensity of $90 \mathrm{db}$ or more from a 2 meter distance. $60 \%$ of males and $53 \%$ of females could perform the task at this intensity from a 2 meter distance. The $Z$ value was computed at 0.422 in which there was no significant difference between the proportion of males and females at a $95 \%$ confidence interval.

Table 7-B. BAH test at 2 meters with intensity of $80 \mathrm{db}$ and above

\begin{tabular}{|c|c|c|}
\hline BAH 2 meters & $80 \mathrm{db}$ & $<80 \mathrm{db}$ \\
\hline Total & $80 \quad(n=93)$ & 13 \\
\hline Males & $44 \quad(n=50)$ & 6 \\
\hline Females & $36 \quad(n=43)$ & 7 \\
\hline
\end{tabular}

Table 7-B shows that 80 out of 93 subjects (86\%) were able to achieve an intensity of $80 \mathrm{db}$ or more. $88 \%$ of whom were male and $84 \%$ were females. A z-value of 0.294 was computed in which there was no significant difference between the proportion of males and females who could reach $80 \mathrm{db}$ or more.

Table 7-C. BAH test at 2 meters with intensity of $70 \mathrm{db}$ and above

\begin{tabular}{lcc}
\hline BAH 2 meters & $\mathbf{7 0 ~ d b}$ & $<70 \mathbf{d b}$ \\
\hline Total & $90(\mathrm{n}=93)$ & 3 \\
Males & $49(\mathrm{n}=50)$ & 1 \\
Females & $41(\mathrm{n}=43)$ & 2 \\
\hline
\end{tabular}

As presented in Table 7-C, there were 90 out of 93 subjects $(97 \%)$ who could reach a $70 \mathrm{db}$ intensity with the sound "baah" uttered from a 2 meter distance. $98 \%$ of males and $95 \%$ of females could reach this intensity from the stated distance. A Z value of 0.133 was calculated at a $95 \%$ confidence interval in which there was no significant difference between the two proportions.

Table 8-A. Psst test at 1 meter with intensity of $90 \mathrm{db}$ and above

\begin{tabular}{lcc}
\hline Psst $\mathbf{1}$ meter & $\mathbf{9 0 ~ d b}$ & $<\mathbf{9 0 ~ d b}$ \\
\hline Total & $8(\mathrm{n}=93)$ & 85 \\
Males & $8(\mathrm{n}=50)$ & 42 \\
Females & $0(\mathrm{n}=43)$ & 43 \\
\hline
\end{tabular}

The values shown on Table 8-A say that when the "psst" sound was tested at a one meter distance, 8 out of 93 subjects could achieve an intensity level of $90 \mathrm{db}$ or more. Only $16 \%$ of males and none of females could achieve this intensity from a one meter distance. The computed $\mathrm{Z}$ value was 2.373 which garnered significantly different results between the two proportions at a $95 \%$ confidence interval. Thus, consistency may again be questionable with regard to using the sound "psst" as basis for testing.

Table 8-B. Psst test at 1 meter with intensity of $80 \mathrm{db}$ and above

\begin{tabular}{lcc}
\hline Psst $\mathbf{1}$ meter & $\mathbf{8 0 ~ \mathbf { ~ b }}$ & $<\mathbf{8 0 ~ d b}$ \\
\hline Total & $34(\mathrm{n}=93)$ & 59 \\
Males & $22(\mathrm{n}=50)$ & 28 \\
Females & $12(\mathrm{n}=43)$ & 31 \\
\hline
\end{tabular}

As tabulated in Table 8-B, 34 out of the 93 subjects (37\%) achieved an intensity of $80 \mathrm{db}$ or more. $44 \%$ of males and $28 \%$ of females were able to achieve this intensity. The computed $\mathrm{Z}$ value was 1.39 which showed no significant difference between the male and female proportions.

Table 8-C. Psst test at 1 meter with intensity of $70 \mathrm{db}$ and above

\begin{tabular}{lcc}
\hline Psst $\mathbf{1}$ meter & $\mathbf{7 0 ~} \mathbf{d b}$ & $<\mathbf{7 0 ~ d b}$ \\
\hline Total & $58(\mathrm{n}=93)$ & 35 \\
Males & $34(\mathrm{n}=50)$ & 16 \\
Females & $24(\mathrm{n}=43)$ & 19 \\
\hline
\end{tabular}

The data in Table 8-C shows that 58 out of 93 subjects $(62 \%)$ were able to achieve an intensity of $70 \mathrm{db}$ or more when the "psst" sound was produced from a one meter distance. $68 \%$ of males and $56 \%$ of females were able to reach this intensity. The computed $Z$ value was 0.995 which showed no significant difference between the two proportions. 
Table 8-D. Psst test at 1 meter with intensity of $60 \mathrm{db}$ and above

\begin{tabular}{lcc}
\hline Psst $\mathbf{1}$ meter & $\mathbf{6 0} \mathrm{db}$ & $<60 \mathrm{db}$ \\
\hline Total & $82(\mathrm{n}=93)$ & 11 \\
Males & $46(\mathrm{n}=50)$ & 4 \\
Females & $36(\mathrm{n}=43)$ & 7 \\
\hline
\end{tabular}

Table 8-D shows that when done from a one meter distance, 82 out of 93 subjects (88\%) were able to reach an intensity of $60 \mathrm{db}$ or more while doing the "psst" test. $92 \%$ of males and $84 \%$ of females. The computed $Z$ value was 0.911 which showed no significant difference between the two proportions.

Table 9-A. Psst test at 2 meters with intensity of $90 \mathrm{db}$ and above

\begin{tabular}{lcc}
\hline Psst $\mathbf{2}$ meter & $\mathbf{9 0} \mathrm{db}$ & $<\mathbf{9 0} \mathrm{db}$ \\
\hline Total & $5(\mathrm{n}=93)$ & 88 \\
Males & $4(\mathrm{n}=50)$ & 46 \\
Females & $1(\mathrm{n}=43)$ & 42 \\
\hline
\end{tabular}

In Table 9-A, the values show that when done from a 2 meter distance, 13\% were able to utter the sound "Psst" at 90 $\mathrm{db}$ SPL. $8 \%$ among males and $2 \%$ among females accordingly. A z-value of 0.748 at $95 \%$ confidence interval was computed which showed no significant difference between males and females who could achieve an intensity of $90 \mathrm{~b}$ or more when uttering the sound "psst".

Table 9-B. Psst test at 2 meters with intensity of $80 \mathrm{db}$ and above

\begin{tabular}{lcc}
\hline Psst 2 meter & $\mathbf{8 0 ~ d b}$ & $<\mathbf{8 0 ~ d b}$ \\
\hline Total & $17(\mathrm{n}=93)$ & 76 \\
Males & $13(\mathrm{n}=50)$ & 37 \\
Females & $4 \quad(\mathrm{n}=43)$ & 39 \\
\hline
\end{tabular}

Table 9-B shows that when done at 2 meters, $18 \%$ were able to produce the sound "psst" at $80 \mathrm{dbSPL}$ or more. Achieving a value of $26 \%$ among males and $9 \%$ among females, respectively. A $z$ value of 1.808 at $95 \%$ confidence interval was computed in which there was no significant difference between males and females who could utter the sound "psst" at $80 \mathrm{db}$ or more.

Table 9-C. Psst test at 2 meters with intensity of $70 \mathrm{db}$ and above

\begin{tabular}{lcc}
\hline Psst 2 meter & $\mathbf{7 0 ~ d b}$ & $<\mathbf{7 0 ~ d b}$ \\
\hline Total & $47(n=93)$ & 46 \\
Males & $27(n=50)$ & 23 \\
Females & $20(n=43)$ & 23 \\
\hline
\end{tabular}

The data shown in Table 9-C shows that when done at 2 meters, 51\% were able to say "psst" at $70 \mathrm{db}$ SPL. $54 \%$ among males and $47 \%$ among females. A z-value of 0.512 at $95 \%$ confidence interval was computed in which there was no significant difference between males and females who could reach an intensity of $70 \mathrm{db}$ or more.

The results of the tests done indicate that using the word "Baah" is better than "Psst" in terms of its capability to stimulate a wide range of sound frequencies, its possibility of being reproduced consistently and its probability of being vocalized louder than 90db SPL.

The spectral sound frequency range of the "Baah" sound is wider. When this sound is produced, hair cells in the cochlea that are sensitive to high frequencies and hair cells that are sensitive to low frequencies have the potential to be stimulated since this sound stimulates the low to high sound frequency range $(150-5000 \mathrm{~Hz})$. On the other hand, the use of the "Psst" sound is limited to only high frequency $(2000-15000 \mathrm{~Hz})$ sound stimulation in which it may have the ability of stimulating cochlear hair cells that perceive only high frequency sounds.

The mean intensity value of "Baah" is significantly higher than that of "Psst". The differences in mean intensity between males and females is not significantly different for the "Baah" test but is significantly different for the "Psst" test.

Majority of the subjects who participated in the study could produce the word "Baah" at an intensity of $90 \mathrm{db}$ and above but the majority of subjects could not produce the word "Psst" at an intensity of $90 \mathrm{db}$. There was a significant difference in the "Psst" test when it was done by a male as opposed to when it was done by a female at this particular intensity. Bearing this in mind, newborns who cannot perceive sound levels from a cutoff of $90 \mathrm{db}$ SPL in both the low and high frequencies may be classified as profoundly deaf.

\section{Limitations of the Study}

The test environment, such as the baby's home or the barangay health center, can affect the test result especially when the test is to be done in a noisy place. Adequate training in order to reproduce the sound well is needed in order to give a more reliable result. Very intense sounds may give false positive results due to the vibratory effect that it may produce when it stimulates the low frequency sound spectrum. A comparative test with the current standards for universal newborn hearing screening, such as the OAE and the ABR tests, are needed in order to determine the accuracy and usefulness of the voice test in an actual newborn. 


\section{Conclusion}

This study indicates that the voice test using the word "Baah" may be considered as an alternative hearing screening test. This test may also be used as a tool in order to educate parents and community health workers, about the necessity of having a newborn hearing screening done and about need for early intervention in children identified with profound hearing loss.

\section{References}

1. American Academy of Pediatrics, Joint Committee on Infant Hearing. Year 2007 Position Statement: Principles and guidelines for early hearing detection and intervention programs. Pediatrics. 2007; 120(4):898-921.

2. Philippine Commission on Women, Statistics on Filipino Women and Men's Health and Family Planning: research findings [Online]. 2006 [cited 2012 July]. Available from http://pcw.gov.ph/statistics/201205/statistics-filipino-women-and-menshealth-and-family-planning.

3. Tibussek D, Meister H, Walger M, Foerst A, von WH. Hearing loss in early infancy affects maturation of the auditory pathway. Dev Med Child Neurol. 2002; 44(2):123-9.

4. Pirozzo S, Papinczak T, Glasziou P. Whispered voice test for screening for hearing impairment in adults and children: systematic review. BMJ. 2003; 327(7421):967.

5. Todd NW. Hearing Assessment in Infants and Children. In: Cotton RT, Myer CM, eds. Practical Pediatric Otolaryngology. Philadelphia: Lippincott-Raven; 1999. pp. 199-215.

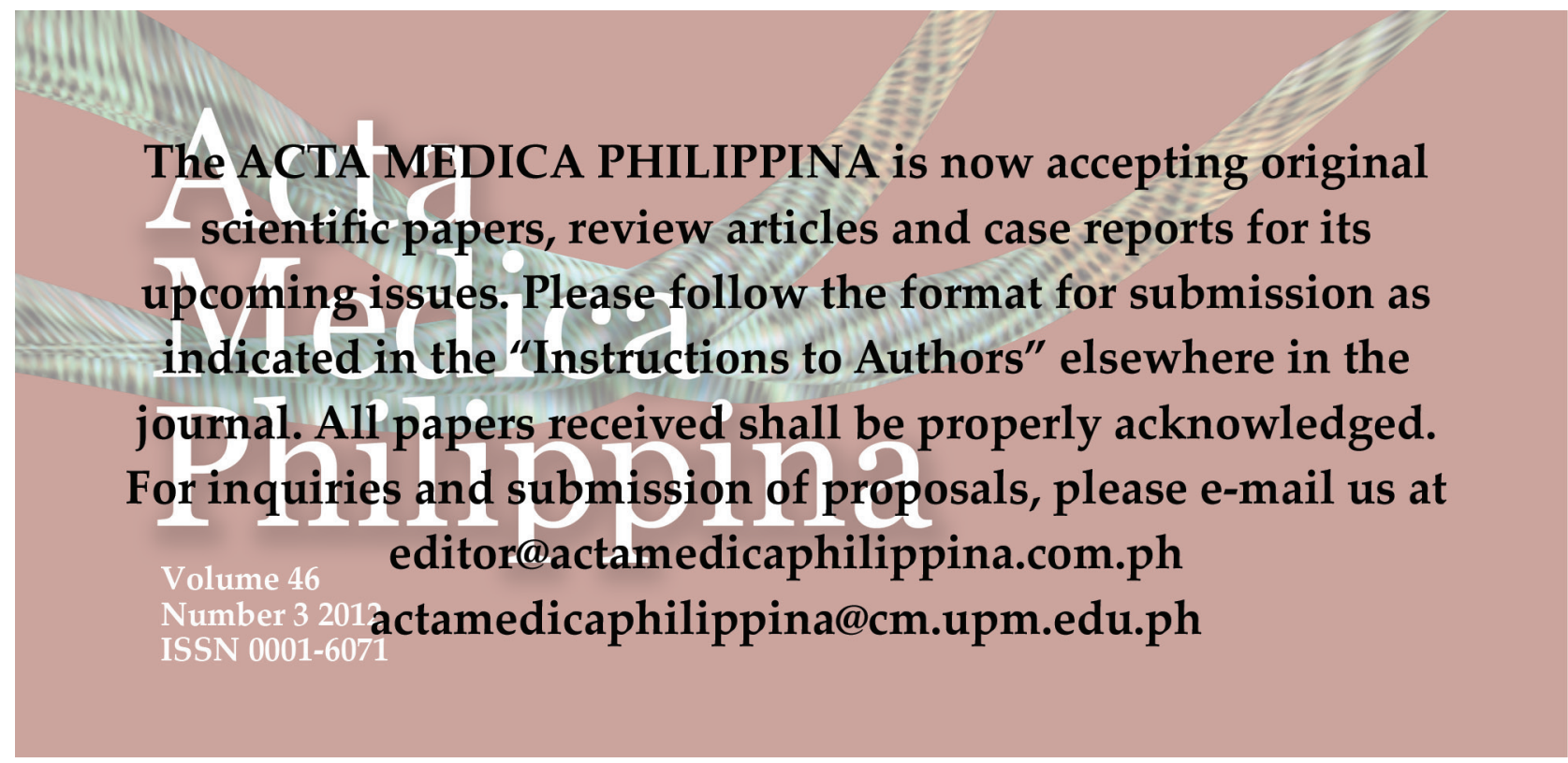

